\title{
Nucleotide Regulation of Goblet Cells in Human Airway Epithelial Explants: Normal Exocytosis in Cystic Fibrosis
}

\author{
Michael I. Lethem, Maria L. Dowell, Michael Van Scott, ${ }^{1}$ James R. Yankaskas, \\ Thomas Egan, Richard C. Boucher, and C. William Davis \\ Departments of Medicine, Surgery, and Physiology, University of North Carolina, Chapel Hill, North Carolina
}

\begin{abstract}
The regulation of mucin secretion by airway goblet cells is poorly understood and the receptor-based regulatory mechanisms have not been described in human airways. In the present study, we report that extracellular triphosphate nucleotides regulate the rate of granule release from goblet cells in both normal and cystic fibrosis (CF) airway epithelial explants. Explants isolated from nasal and tracheobronchial tissues were mounted in perfusion chambers and the secretory activity was assessed by videomicroscopic determination of degranulation in single goblet cells and by ELISA determination of mucins secreted into the mucosal perfusate. Baseline degranulation was measured at 0.05 degranulation events $(\mathrm{DE}) / \mathrm{min}$. In normal goblet cells, mucosal ATP $\left(10^{-4} \mathrm{M}, n=17\right)$ induced a biphasic secretory response comprising $29.1 \pm 4.9 \mathrm{DE}$ during the first $5 \mathrm{~min}$, with an initial rate of $118.2 \pm 10.2 \mathrm{DE} / \mathrm{min}$. Mucosal UTP $\left(10^{-4} \mathrm{M}, n=9\right)$ induced a similar response to ATP (initial rate: $89.2 \pm 23.9 \mathrm{DE} / \mathrm{min}, 17.9 \pm 5.1 \mathrm{DE}$ in $5 \mathrm{~min}$ ), but mucosal 2-MeSATP was not an effective agonist (initial rate: $1.5 \pm 1.4 \mathrm{DE} / \mathrm{min}, 2.3 \pm$ $0.5 \mathrm{DE}$ in $5 \mathrm{~min}$ ). Determination of mucins by ELISA confirmed that both ATP and UTP induced similar secretory responses but that 2-MeSATP was not effective. In CF explants, mucosal UTP $\left(10^{-4} \mathrm{M}, n=\right.$ 6) induced similar responses to those observed in normal tissues (initial rate: $82.5 \pm 27.5 \mathrm{DE} / \mathrm{min}, 18.8 \pm$ 4.1 DE in $5 \mathrm{~min}$ ). We conclude that human nasal and tracheobronchial goblet cells are stimulated by mucosal nucleotides, probably via a $5^{\prime}$-nucleotide receptor, and that this response is unaffected by $\mathrm{CF}$.
\end{abstract}

Mucus secretion into the airway is a central component in the process of mucociliary clearance, the respiratory defense mechanism that traps inhaled foreign material in mucus and removes it from the lung by the action of beating cilia. The major determinants of the physical properties of mucus are glycoproteins (mucins), which are traditionally considered to be derived from two principal sources: mucous cells of the submucosal glands and goblet cells situated in the epithelium lining the airways. More recently, evidence has accrued that similar glycoconjugates are released from the surface of the airway epithelial cells in response to the action of various proteases $(1,2)$. The presence of multiple sources of mucin in the respiratory tract has hindered investigation of the regulation of secretion from specific cell types, in particular

(Received in original form December 30,1992 and in revised form May 1, 1993)

Address correspondence to: Dr. M. I. Lethem, Department of Pharmacy, University of Brighton, Lewes Rd., Moulsecoomb, Brighton, East Sussex BN2 4GJ, United Kingdom.

Abbreviations: adenosine-5'-triphosphate, ATP; cystic fibrosis, CF; degranulation events, DE; enzyme-linked immunosorbent assay, ELISA; nonadrenergic-noncholinergic, NANC; phosphate-buffered saline, PBS; sodium dodecyl sulfate, SDS; Tris-buffered saline, TBS.

${ }^{1}$ Current address: Department of Physiology, East Carolina University School of Medicine, Greenville, NC 27858.

Am. J. Respir. Cell Mol. Biol. Vol. 9. pp. 315-322, 1993 goblet cells. Most studies of respiratory mucus secretion have employed large airways that contain a greater volume of submucosal glands than of goblet cells and have, therefore, provided information primarily about the regulation of submucosal glands secretion (3). These studies have indicated that submucosal glands in several species, including human, are regulated by multiple systems including cholinergic, adrenergic, and nonadrenergic-noncholinergic (NANC) pathways (4-7).

In contrast to submucosal glands, the regulation of secretion from goblet cells is poorly understood, mainly due to difficulty in collecting secretions from these cells without contamination from glandular sources. Such studies are of particular importance because in the small airways, which are the principal site of involvement in obstructive airways disease associated with hypersecretion, goblet cells are the sole source of mucin. A morphometric study in intact guinea pigs suggested that goblet cells are under neural control, probably via cholinergic and NANC pathways (8). Additionally, studies employing mucin-secreting primary cultures have suggested that goblet cells are regulated by plateletactivating factor (9) and adenosine-5'-triphosphate (ATP) (10), in cat and hamster, respectively. Recently, this laboratory reported a technique to isolate and maintain intact sheets of superficial epithelium in culture. Goblet cells in these explant preparations were shown by videomicroscopy to undergo degranulation in response to ATP (11). 
In this article, we report the first studies investigating the regulation of secretion from goblet cells in explanted human superficial nasal and tracheobronchial epithelium. The secretory activity of goblet cells within the explants was monitored both by direct visualization of the cells, using videomicroscopy, and by immunologic quantitation of secreted mucins, using an enzyme-linked immunosorbent assay (ELISA). These techniques have been employed to investigate the secretory response of both normal and cystic fibrosis (CF) goblet cells to activation by mucosal 5'-nucleotides.

\section{Materials and Methods}

\section{Isolation and Culture of Airway Epithelial Explants}

Inferior nasal tissues were obtained from six patients undergoing elective excision of turbinates for nasal obstruction. Human tracheobronchial airways (distal trachea and first to third generation bronchi) were dissected from tissues removed from five patients (three with CF, one with bronchiolitis, and one with primary pulmonary hypertension) undergoing lung transplantation at the University of North Carolina and at $1 \mathrm{~h}$ postmortem from one patient with no apparent lung disease. Although we are interested in investigating the effects of several 5'-nucleotides on goblet cell function in CF, the availability of such tissues is limiting. Consequently, we chose to emphasize studies with UTP over ATP on CF tissues because of its potentially greater therapeutic value (see reference 27). All procedures were reviewed and approved by the University of North Carolina Committee for the Protection of Rights of Human Subjects.

Human airway epithelial explants were isolated and cultured using minor modifications to the technique previously described for canine tracheal epithelium (11). Briefly, tissues were pinned out with the mucosal surface uppermost. A solution containing collagenase (100 Mandl U/ml; BoehringerMannheim, Indianapolis, IN) and dispase (1 U/ml, grade II; Boehringer-Mannheim) in phosphate-buffered saline (PBS) was injected under the epithelium, and the tissue was bathed in Joklik's MEM containing: $1 \mathrm{mM} \mathrm{CaCl}, 1 \mathrm{mM}$ dithiothreitol (Sigma Chemical Co., St. Louis, MO), $0.01 \%$ DNAse 1 (Sigma), and hexokinase (1 U/ml; Boehringer-Mannheim). After a 30 -min incubation at $37^{\circ} \mathrm{C}$ in a $5 \% \mathrm{CO}_{2}$ incubator, the epithelium was scraped from the tissue with a glass coverslip and suspended in bathing medium. The suspended sheet of epithelium was cut into 3- to 5-mm pieces, which were explanted, mucosal surface uppermost, onto a synthetic Vitrogen (Celtrix Pharmaceuticals, Santa Clara, CA)coated nitrocellulose substrate and allowed to attach by incubation overnight at air:liquid interface in $5 \% \mathrm{CO}_{2}$ at $37^{\circ} \mathrm{C}$. The culture medium in contact with the basolateral surface of the substrata was hormone-supplemented Ham's F1 2 containing 3T3-conditioned medium, as described previously (11), with the addition of hexokinase $(1 \mathrm{U} / \mathrm{ml}$; BoehringerMannheim). After overnight incubation, the explants were washed by immersion in culture medium and returned to airliquid interface culture. The explants were maintained in this configuration with daily changing of the medium until used, usually within 2 to 3 days.

\section{Perfusion and Measurement of Secretory Activity}

For single-cell studies, airway epithelial explants were mounted and perfused in Ussing chambers and, after a 30- min equilibration period, the secretory activity was monitored by videomicroscopy as previously described (11). In experiments involving the immunologic measurement of secreted mucins, explants attached to nitrocellulose substrata were mounted in Ussing chambers with a serosal volume of $80 \mu \mathrm{l}$ and a mucosal volume of $40 \mu \mathrm{l}$. The explants were supported serosally by a 3-mm filter (MF-Millipore) and were held in place by a tissue-retaining ring possessing a 3-mm opening into the mucosal half-chamber. The explant was continuously perfused $(100 \mu \mathrm{l} / \mathrm{min})$ on both sides with medium (Ham's F1 2 to which had been added $15 \mathrm{mM}$ sodium bicarbonate and $1 \mathrm{mM}$ calcium chloride and the resulting mixture readjusted to isotonicity), warmed to $37^{\circ} \mathrm{C}$, and equilibrated with $5 \% \mathrm{CO}_{2}: 95 \% \mathrm{O}_{2}$. Each experiment commenced with an initial 90-min equilibration period, which was followed by a 30-min baseline period before agonist was added to the mucosal perfusate. During both baseline and agonist exposure periods, samples of mucosal perfusate were collected at 5-min intervals by a fraction collector (Buchler Instruments, Lenexa, KS) and stored at $-20^{\circ} \mathrm{C}$ for subsequent analysis by mucin ELISA.

\section{Mucin ELISA Procedure}

An ELISA procedure was developed using the previously described anti-mucin monoclonal antibody 17B1 $(12,13)$. Samples $(50 \mu \mathrm{l})$ of perfusate or purified human mucin standard $(0$ to $50 \mathrm{ng})$ were bound to $96-$ well microtiter plates (Immulon 2; Dynatech Laboratories, Chantilly, VA) overnight at $4{ }^{\circ} \mathrm{C}$. After washing in PBS containing $0.05 \% \mathrm{vol} / \mathrm{vol}$ Tween 20 and $0.03 \% \mathrm{wt} /$ vol bovine serum albumin $(3 \times 200$ $\mu \mathrm{l})$, unbound sites were blocked by incubation with $200 \mu \mathrm{l}$ of PBS containing $0.05 \mathrm{vol} / \mathrm{vol}$ Tween 20 and 3\% wt/vol bovine serum albumin $\left(2 \mathrm{~h}, 22^{\circ} \mathrm{C}\right)$. The plates were washed as above and incubated with 17B1 primary antibody (50 $\mu 1$, $2 \mathrm{~h}, 22^{\circ} \mathrm{C}$ ) before undergoing further washes. The plates were incubated $\left(1 \mathrm{~h}, 37^{\circ} \mathrm{C}\right)$ with $50 \mu \mathrm{l}$ goat anti-mouse immunoglobulins horseradish peroxidase conjugate (Cappel Research Products, Durham, NC) and washed again as above. The wells were developed by the addition of $150 \mu \mathrm{l}$ $0.01 \% \mathrm{wt} / \mathrm{vol} 3^{\prime} 3^{\prime} 5^{\prime} 5^{\prime}$-tetramethylbenzidine in $0.1 \mathrm{M}$ acetate:citrate buffer, $\mathrm{pH} 6.0$, containing $0.005 \%$ hydrogen peroxide. The reaction was stopped by the addition of $2.35 \mathrm{M}$ sulfuric acid $(50 \mu \mathrm{l})$, and optical density at $450 \mathrm{~nm}$ measured in a Molecular Devices UVmax microplate reader.

\section{Characterization of 17B1 Immunoreactivity}

Immunohistochemical staining with 17B1 antibody was performed on 5-mm sections of paraffin-embedded human bronchus. Sections were deparaffinized, rehydrated, and washed with PBS, prior to blocking with 5\% goat serum for $20 \mathrm{~min}$. The blocked sections were incubated for $30 \mathrm{~min}$ at room temperature with $17 \mathrm{~B} 1$ antibody $(1: 500)$ or nonimmune serum $(5 \%)$ and washed 3 times in PBS. Binding of $17 \mathrm{~B} 1$ was visualized using gold-labeled goat anti-mouse immunoglobulins and silver enhancement ("Auroprobe" and "Intense M"; Amersham, Arlington Heights, IL).

17Bl antibody was characterized further by Western blotting of perfusate from human airways. Human tracheal epithelial explants were mounted in chambers as described for experiments involving immunologic measurement of mucin, and the perfusate was collected. The perfusate and a sample 
of mucin standard were both lyophilized and dissolved in disaggregation buffer $\left(50 \mathrm{mM}\right.$ Tris, $\mathrm{pH} 6.8$, with $\mathrm{H}_{3} \mathrm{PO}_{4}$, containing $2 \%$ sodium dodecyl sulfate [SDS] [wt/vol], $15 \%$ glycerol [wt/vol], 2\% 2-mercaptoethanol [vol/vol], $1 \mathrm{mM}$ EDTA, and $0.02 \%$ bromophenol blue). Approximately $12 \mu \mathrm{g}$ of perfusate material or mucin standard was loaded onto a preformed 4 to $15 \%$ polyacrylamide gel (Bio-Rad Laboratories, Richmond, CA) and electrophoresed in a running buffer

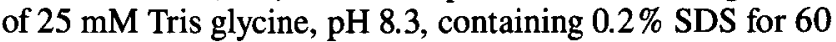
min at a constant current of $110 \mathrm{~mA}$. The gel was blotted onto nitrocellulose membrane in $192 \mathrm{mM}$ glycine, $25 \mathrm{mM}$ Tris, 20\% methanol, pH 8.3, using a Bio-Rad Transblot cell $\left(35 \mathrm{~V}, 12 \mathrm{~h}, 15^{\circ} \mathrm{C}\right)$. The blotted membrane was washed in Tris-buffered saline (TBS)-Tween solution $(200 \mathrm{mM} \mathrm{NaCl}$ and $0.1 \%$ [vol/vol] Tween 20 in $50 \mathrm{mM}$ Tris, $\mathrm{pH} \mathrm{7.4)} \mathrm{and} \mathrm{in-}$ cubated in the same solution containing $5 \%$ (wt/vol) Carnation nonfat dry milk for $60 \mathrm{~min}$ at room temperature. 17B1 antibody was diluted to 1:500 with TBS-Tween-milk and incubated for $60 \mathrm{~min}$ at room temperature. The blot was washed twice in TBS-Tween and incubated with $2^{\circ}$ antibody (peroxidase-conjugated goat anti-mouse immunoglobulins) for $60 \mathrm{~min}$ at room temperature. The blot was washed 3 times in TBS-Tween before being developed using an enhanced chemiluminescence kit (Amersham). Molecular weight measurements were made during Bio-Rad high molecular weight standards run on the same gel and stained with Coomassie Brilliant Blue.

\section{Data Analysis}

Video records obtained during single-cell studies were analyzed using a custom computer program that allowed the observer to record the time of each individual degranulation event within a particular cell (11). In addition, several of the cells studied exhibited initial rates of degranulation that were too rapid for manual analysis and in these cases the first minute of the response was analyzed by the image-processing system through the technique of temporal image subtraction.
This involved acquiring and storing images (two or four frame average) from videotape at 1-s intervals beginning $1 \mathrm{~s}$ prior to the start of the response. These digital images were then analyzed by subtracting sequential pairs, and the resulting images, showing no major detail other than the degranulations that had occurred between the two time periods, were displayed. The degranulations shown in each image were then counted manually and recorded.

Data are presented as mean \pm SEM, and statistical significance between group means was judged by the Student's $t$ test at the 0.05 level of significance.

\section{Materials}

Tissue culture media were obtained from GIBCO BRL (Gaithersburg, MD). Hormones for supplementing culture media were obtained from Collaborative Research (Bedford, MA). ATP and UTP were supplied by Boehringer-Mannheim, and 2-MeSATP was purchased from Research Biochemicals Inc. (Natick, MA). All other chemicals were obtained from Sigma.

\section{Results}

Airway epithelial explants visualized by videomicroscopy, using differential interference contrast optics, appeared as an intact epithelium whose surface was comprised of both ciliated cells, possessing vigorously beating cilia, and goblet cells that were identified by their nonciliated granular appearance (Figure 1). Goblet cells typically were densely packed with several layers of granules that extended from the apical pole several microns into the cell. In general, the goblet cells were of a similar appearance to that previously described for canine airway epithelial goblet cells, with the exception that the granules of human goblet cells were routinely smaller than the 1.4-mm diameter reported for granules in canine airway epithelial explants (11). Owing to the smaller size and tight packing of granules in human goblet cells, it was difficult to resolve the boundaries of individual

Figure 1. Differential interference contrast image of the apical region of two adjacent goblet cells in a human airway epithelial explant. An epithelial explant was mounted in a miniature Ussing chamber and visualized by videomicroscopy. The image was acquired as a 256 -frame average to reduce the effects of beating cilia on image quality. Scale bar is in $\mathrm{mm}$.

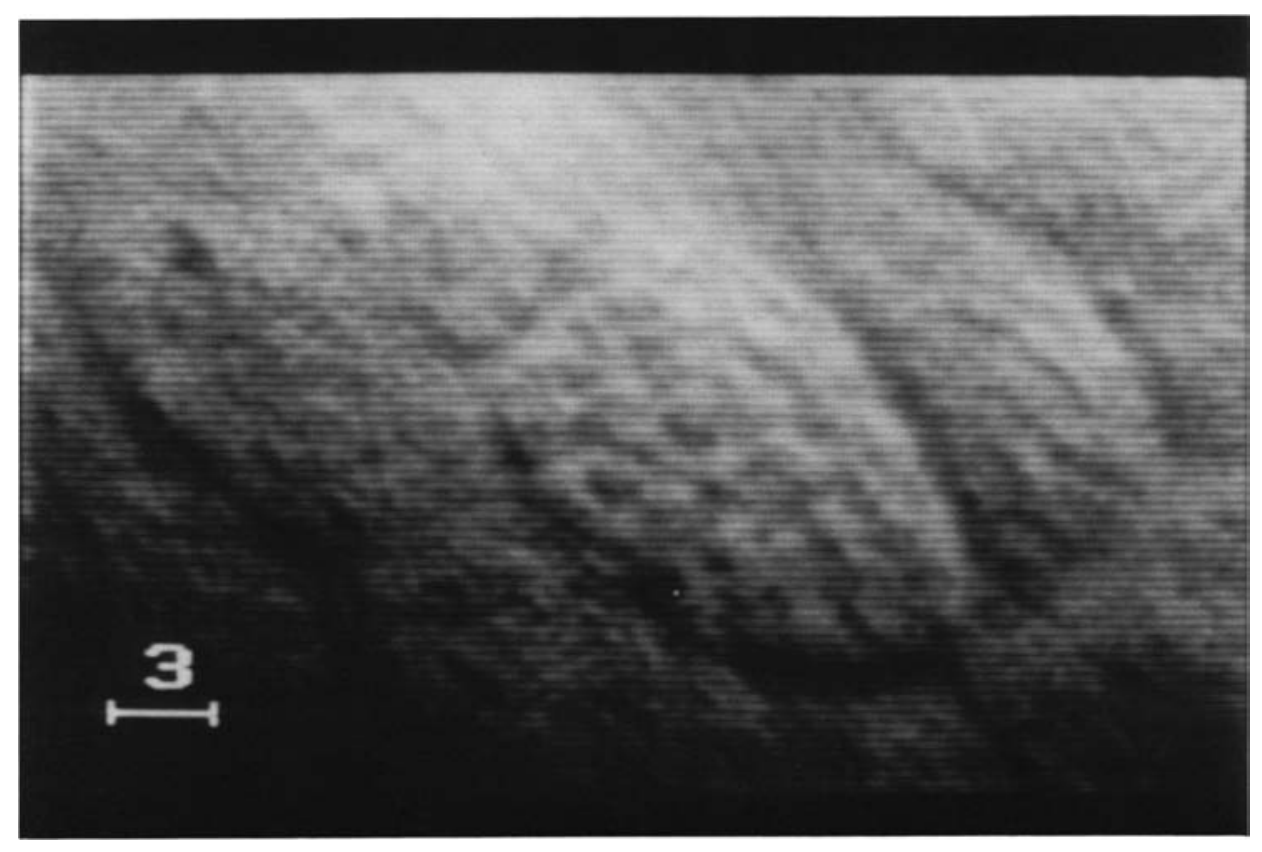




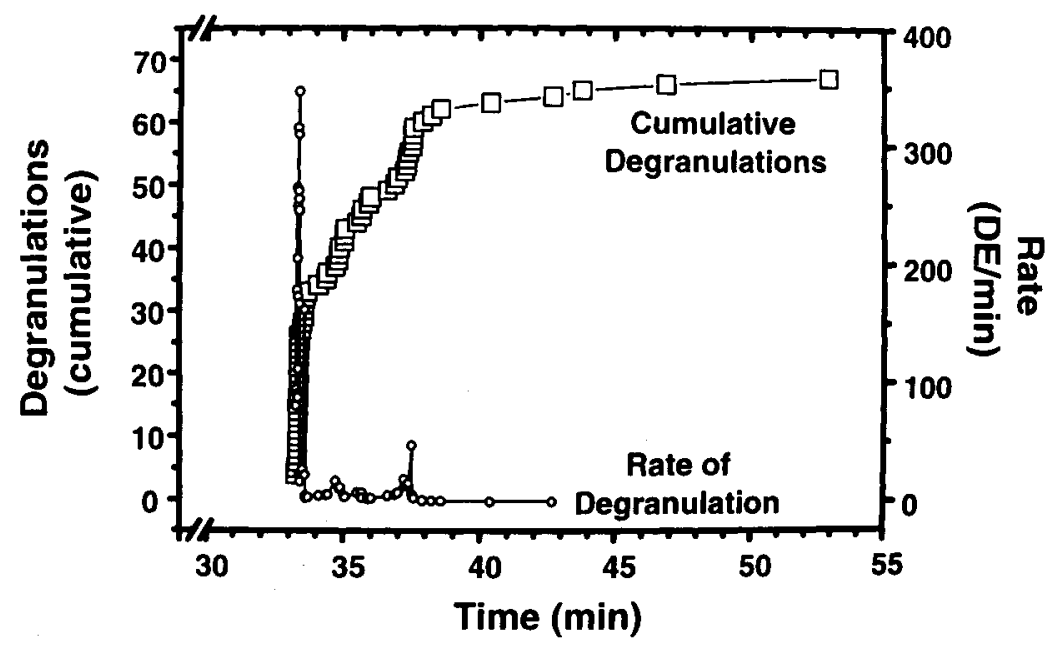

Figure 2. Response of a single human goblet cell to mucosal ATP $\left(10^{-4} \mathrm{M}\right)$. An epithelial explant was mounted and perfused in a miniature Ussing chamber, and a goblet cell visualized by videomicroscopy. Secretory activity was determined by recording the time at which individual degranulations occurred within the cell. Data are expressed as cumulative degranulations (squares) and rate of degranulation (circles). Rates were calculated as 4point least-square fits to cumulative degranulation data. granules in direct Nomarski images, and granule diameters were therefore determined from temporarily subtracted images (e.g., see Figure 3). This analysis yielded a mean diameter for 50 granules in four cells from three explants of $1.0 \pm 0.1 \mathrm{~mm}$.

Exocytosis of individual granules from goblet cells in human explants was observed as the sudden disappearance of a granule from the cell. In each experiment, the baseline rate of degranulation was assessed over a 10 - to 30 -min period. Of the 31 cells from nine non-CF patients studied, the majority (21) exhibited no baseline degranulation events (DE) and most of the remaining cells underwent fewer than five events during the baseline period. From these data, accumulated over a total of $11.1 \mathrm{~h}$ of observation, a mean baseline degranulation rate of $0.05 \pm 0.02 \mathrm{DE} / \mathrm{min} / \mathrm{cell}$ was calculated. This value is the same as that calculated for canine goblet cells under the same conditions (11). No significant difference in baseline activity was observed between nasal and tracheobronchial tissues. In CF explants, a mean baseline degranulation rate of $0.14 \pm 0.08 \mathrm{DE} / \mathrm{min}$ was calculated (eight cells from three patients, $2 \mathrm{~h}$ of observation), a value that is not significantly different from that observed in non-CF explants.

The response of goblet cells to a mucosal challenge with ATP $\left(10^{-4} \mathrm{M}\right)$ was studied in 17 cells in eight non-CF explants isolated from eight tissues (six nasal, two tracheobronchial), a typical response of a single cell being shown in Figure 2. Early in the baseline period, three degranulations were observed; however, the cell was then quiescent for 19 min prior to the switch to mucosal ATP. This maneuver induced an almost immediate increase in secretion, with nearly 70 degranulations observed during the $20 \mathrm{~min}$ that the cell was exposed to ATP. The response exhibited a biphasic pattern comprising an initial burst of very rapid degranulation with a rate in excess of $300 \mathrm{DE} / \mathrm{min}$, after which the rate progressively slowed until a stable rate of approximately 0.4 $\mathrm{DE} / \mathrm{min}$ was achieved. The rapid rate of exocytosis exhibited by goblet cells during the early stages of the response to mucosal ATP can be seen in Figure 3, which depicts the image subtraction analysis of the initial seconds of such a response. The images shown were acquired by subtraction of the image obtained $1 \mathrm{~s}$ prior to the response from images obtained at $1-\mathrm{s}$ intervals during the first $5 \mathrm{~s}$ of the response. The first panel indicates that just prior to the response no degranulations occurred; however, in the next image $(t=1 \mathrm{~s})$, five degranulations, seen as bright spots in the image, are apparent. Images 2 through 5 reveal an additional four, four, two, and one events during each of the subsequent seconds, respectively, indicating that the cell underwent a total of 16 degranulations during the first $5 \mathrm{~s}$ of the response to mucosal ATP.

Comparison of responses obtained with non-CF nasal and tracheobronchial tissues indicated that there was no significant difference in either the number of degranulations during the first $5 \mathrm{~min}$ of the response $(28.0 \pm 5.06 \mathrm{DE}$ and $20.6 \pm 3.4 \mathrm{DE}$, respectively) or the initial rate $(68.1 \pm 26.5$ $\mathrm{DE} / \mathrm{min}$ and $95.4 \pm 30.12 \mathrm{DE} / \mathrm{min}$, respectively). Consequently, the data from both groups were combined for analysis of the responses to different nucleotides. Table 1 describes the responses of non-CF goblet cells to a mucosal challenge with the nucleotides ATP, UTP, or 2-MeSATP, and CF goblet cells challenged with UTP. All nucleotides were used at $10^{-4} \mathrm{M}$, a concentration that has been found to induce near maximal responses in ion transport and inositol phosphate production in human airway epithelia $(14,15)$. All cells challenged with ATP or UTP responded by degranulation. The magnitude of the response was variable, however, ranging from two to 84 degranulations during the first $5 \mathrm{~min}$ of the response. Responses to ATP or UTP were comparable, both in terms of the number of degranulations and the initial rate at which these occurred. In contrast to the striking responses obtained with ATP and UTP, the $P_{2 Y}$-purinergic receptor agonist 2-MeSATP failed to induce similar rates of degranulation, the number of degranulations being only 5 to $10 \%$ of that achieved with ATP or UTP. The response of goblet cells in CF explants challenged with mucosal UTP was similar to that observed in non-CF cells, both in terms of the initial rate of degranulation and the overall extent of degranulation. In addition, both cells in a CF explant challenged with mucosal ATP responded robustly (71 and $62 \mathrm{DE}$ in the initial $5 \mathrm{~min}$ ), a pattern of degranulation that is similar to the ATP response in non-CF cells. 


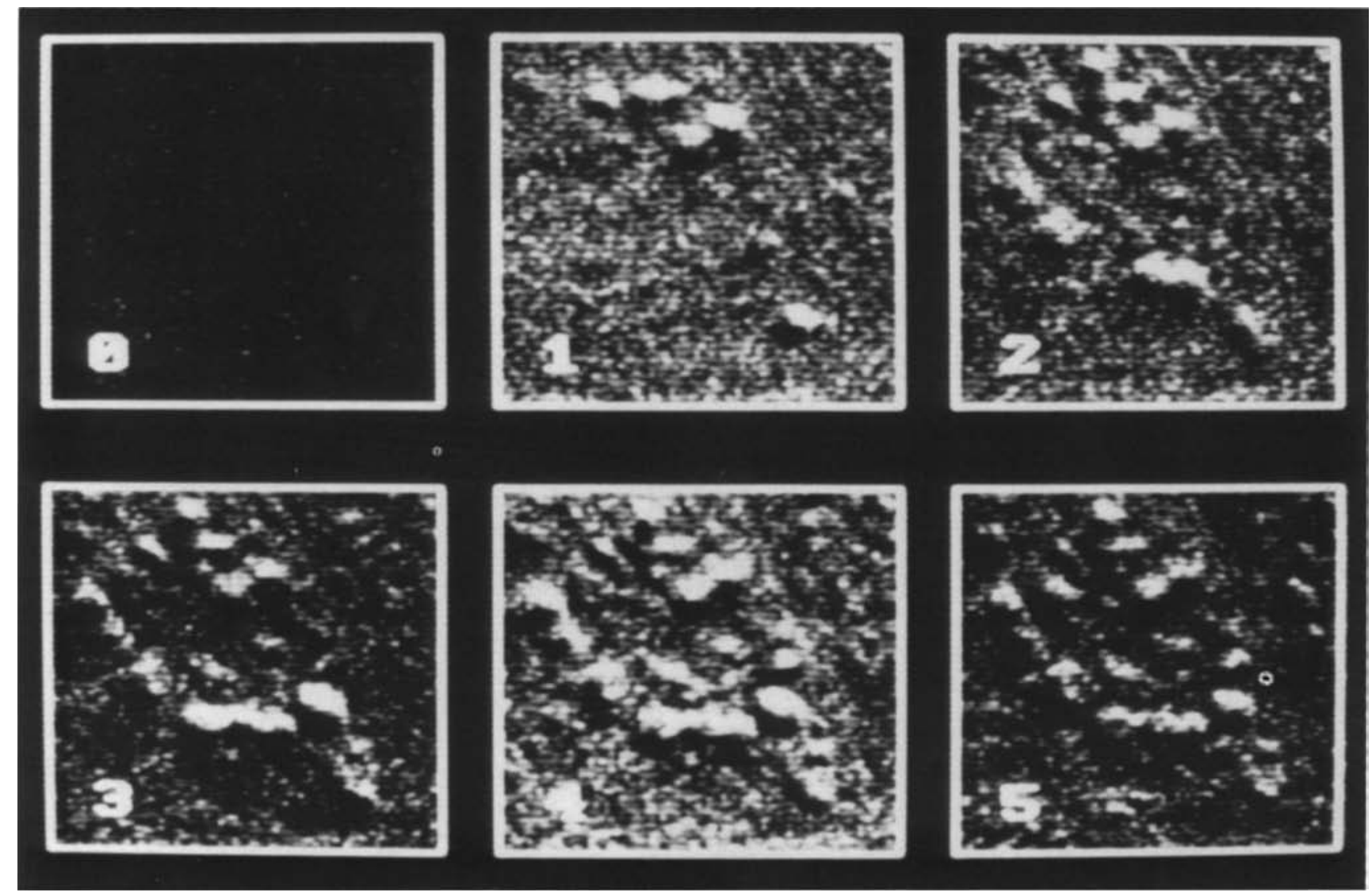

Figure 3. Analysis of the initial response shown in Figure 2, by image subtraction. Images were obtained by subtracting an image (twoframe average) obtained $2 \mathrm{~s}$ prior to the response from similar images obtained at 1-s intervals for the first $5 \mathrm{~s}$ of the response (panels 0 through 5). The displayed results show individual degranulations as bright spots.

As shown in Figure 4, the stimulation of goblet cell degranulation by nucleotides was associated with an increase in the release of mucin glycoprotein as measured by ELISA. In each experiment, nucleotide $\left(10^{-4} \mathrm{M}\right)$ was perfused onto the tissue either mucosally or bilaterally after a 30 -min baseline period and, because no difference between mucosal and bilateral response was observed, Figure 4 depicts the combined data. As was seen with the single-cell studies, both ATP and UTP were capable of inducing the secretion of mucin from the epithelial explants and appeared to possess a similar efficacy. Moreover, 2-MeSATP did not result in increased mucin secretion, a finding that is in agreement with the single-cell studies (Table 1). In contrast to the rapid onset of degranulation in response to ATP and UTP observed in single cells, the response to these agents in whole explants was maximal 10 min after the addition of nucleotide to the perfusate. This, however, is probably a reflection of the longer washout time of the perfusion system used in the whole explant studies ( 4 min versus $30 \mathrm{~s}$ ) and the time required for dispersion of the freshly secreted mucin into the perfusion medium.

In whole explant studies, ATP or UTP induced a 2-fold increase in secretion, which is considerably smaller than the greater than 100-fold increase in degranulation obtained in

TABLE 1

Response of human goblet cells to mucosal nucleotides $\left(10^{-4} \mathrm{M}\right)$ *

\begin{tabular}{lcccc}
\hline & $\begin{array}{c}\text { ATP } \\
\text { (Normal) }\end{array}$ & $\begin{array}{c}\text { UTP } \\
\text { (Normal) }\end{array}$ & $\begin{array}{c}\text { UTP } \\
\text { (CF) }\end{array}$ & 6 \\
\hline Number of cells $(n)$ & 17 & 9 & 11 \\
Degranulations during initial & & $17.9 \pm 5.1$ & $18.8 \pm 4.1$ & $2.3 \pm 0.5$ \\
$\quad 5$ min (DE/cell) & $29.1 \pm 4.9$ & $89.2 \pm 23.9$ & $82.5 \pm 27.5$ & $1.5 \pm 1.4^{\dagger}$ \\
Initial rate (DE/min) & $118.2 \pm 10.2$ & &
\end{tabular}

Definition of abbreviation: $\mathrm{DE}=$ degranulation event

* For details of the experimental procedure, see Figure 2 .

$\dagger$ Different from ATP $(P<0.001)$. 


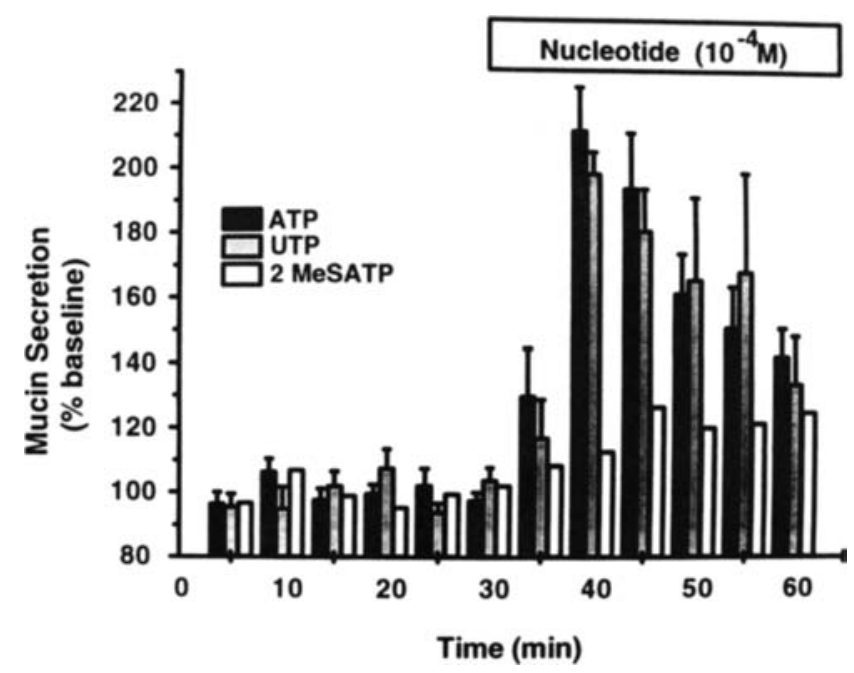

Figure 4. Effect of nucleotides $\left(10^{-4} \mathrm{M}\right)$ on secretion from nonCF human airway epithelial explants. Explants were mounted in Ussing chambers and continuously perfused. Samples of mucosal perfusate (collected over $5 \mathrm{~min}$ ) were analyzed for mucin content by ELISA. Nucleotide (ATP: $n=8$, UTP: $n=5,2$-MeSATP: $n=$ 2) was added to the perfusate after an initial 30 -min baseline period.

single-cell studies. This discrepancy is probably due to differences in the measured level of baseline secretion which was very low in the case of degranulation $(0.05 \mathrm{DE} / \mathrm{min})$ and high in the case of ELISA studies $(1.30 \pm 0.15 \mu \mathrm{g} / \mathrm{ml})$. To investigate the origin of this high baseline, the antibody used in the ELISA (17B1) was characterized further by immunohistochemistry and Western blotting of the perfusate (Figure 5). Antibody staining of human bronchial sections (Figures $5 \mathrm{~A}$ and $5 \mathrm{~B}$ ) shows that antibody 17B1 stained the mucin granules within individual goblet cells of the superficial epithelium. In addition, however, intense staining of the apical surface of ciliated cells was observed. Western blotting with antibody 17B1 (Figure 5C) revealed that the antibody stained the mucin standard and that this was predominantly located at the origin of the gel. Nevertheless, considerable smearing down to an $M_{\mathrm{r}}$ of approximately $200 \mathrm{kD}$ was observed, probably due to the fact that this standard is a reduced mucin purified from CF sputum and hence would be expected to contain significant levels of highly degraded mucin. In contrast, immunoreactivity of the perfusate showed a tight band at the origin probably representing undegraded mucins. Furthermore, a broad band of heterogeneous staining was observed in the range of $M_{\mathrm{r}} 50$ to $150 \mathrm{kD}$, which is below that of the most degraded mucins present in the mucin standard.

\section{Discussion}

The presence of multiple sources of airway mucin in intact animals and whole airway preparations has resulted in studies employing these systems providing little specific information about the regulation of goblet cells. More recently, the availability of airway epithelial cell cultures containing goblet-like cells $(9,11,16)$ has provided the opportunity for studies of this cell type in nonhuman species. Several agents have been reported to regulate mucin secretion from goblet
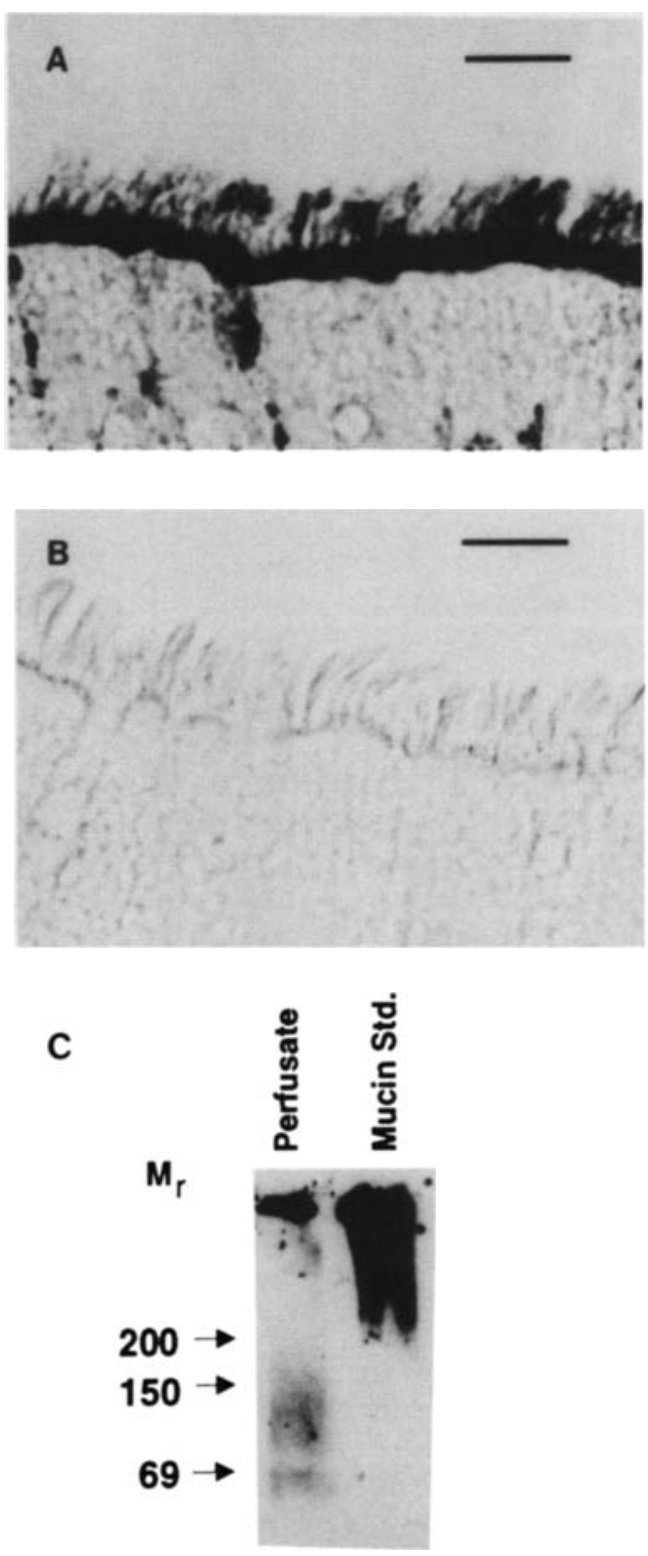

Figure 5. Characterization of $17 \mathrm{~B} 1$ monoclonal antibody. Sections of human bronchus $(5 \mathrm{~mm})$ were stained with $17 \mathrm{Bl}$ antibody (A) or non-immune serum (B) and developed with gold-labeled $2^{\circ}$ antibody as described in MATERIALS AND METHODS. Bar $=10 \mathrm{~mm}$. For Western blotting with 17B1 (C), lyophilized perfusate from explants mounted in chambers of mucin standard was electrophoresed on a 4 to $15 \%$ gradient SDS-PAGE gel and blotted onto nitrocellulose. The blotted membrane was blocked and incubated with 17B1 antibody (1:500) followed by peroxidase-conjugated secondary antibody. Bound antibody was detected by the chemiluminescence method.

cells, including elastase (17), cholinergic and possibly adrenergic stimuli (8), tachykinins (18), platelet-activating factor $(9)$, and purinergic compounds $(10,11)$. The possibility of species variability in expression of regulatory pathways in epithelia, however, requires that stimuli be assessed directly in human airways. Unfortunately, difficulties in the culture of well-differentiated goblet cells has resulted in a lack of data regarding the regulation of goblet cells in humans. 
The results presented here indicate clearly that the technique of isolating and explanting intact sheets of superficial epithelium as described previously for the study of goblet cells in canine trachea (11) is also applicable to human airways. This explant preparation has the advantage over the mucin-producing primary cultures of human airway epithelium that cellular differentiation occurs through the normal processes in the host organism. Furthermore, the lack of alteration in morphology (11) during the isolation and explantation procedures suggests that tissue damage is minimal, increasing the likelihood that the physiologic processes exhibited by the explants will accurately model those of the native tissue.

In addition, this study extends the previous work in canine tissue (11) by indicating that the degranulation observed in single-cell studies is associated with the release of immunologically identifiable mucins. The discrepancy in baseline levels of secretion between single-cell studies and those in whole explants suggests that the 17B1 antibody is identifying other material, in addition to mucins released by degranulation. This is supported by the characterization of 17B1 immunoreactivity (Figure 5). It is clear that in addition to the mucin granules of goblet cells antibody 17B1 strongly recognizes an epitope on the apical surface of ciliated cells. This observation is supported by a report from Wu and co-workers in which, in addition to staining of goblet cells, some staining of the epithelial surface with 17B1 is visible (19, Figure 6). The Western blot of perfusate indicates that in addition to the presence of a band at the origin, representing high molecular weight mucins, there is a heterogeneous signal of $M_{\mathrm{r}} 50$ to $150 \mathrm{kD}$. The identity of this low molecular weight material is not clear; however, it is unlikely to be proteolytically degraded mucins since this material is smaller than glycosylated regions (T-domains), which are the smallest units produced experimentally by extensive proteolytic digestion of mucins $(20,21)$. In addition, the presence of low molecular weight immunoreactivity in the perfusate indicates that nonmucin material that reacts with the antibody is released from the explants. Thus, it seems probable that the high baseline in whole explants is probably due to the release of nonmucin components that cross react with antibody $17 \mathrm{~B} 1$.

This study indicates that luminal triphosphate nucleotides are highly effective regulators of mucin granule release in human goblet cells. Both the biphasic pattern of degranulation and the magnitude of response induced by mucosal ATP are similar to those previously reported for canine epithelial explants (11), suggesting that ATP is acting in both tissues through the same mechanism. Previous studies in hamster (10) and dog (11) have indicated that the action of ATP on goblet cells is mediated via $P_{2}$-purinergic receptors on the cell surface, although in neither study was it clear which specific subclass of receptor was involved. From the canine study, it seems probable that the dominant response is mediated via a single class of ATP-specific receptors on the apical surface, while the basolateral surface may be populated with both ATP receptors and other purinergic receptors.

The present study focuses on the responses to apically applied purinergic compounds mediated through a $P_{2}$-purinergic receptor. Based on the relative potencies of various agents, four subclasses of $P_{2}$-purinoreceptors $\left(P_{2 x}, P_{2 Y}, P_{2 T}\right.$, and $\left.\mathbf{P}_{2 z}\right)$ have been proposed $(15,22,23)$. In addition, a $5^{\prime}$ nucleotide receptor sensitive to both purine (ATP) and pyrimidine (UTP) triphosphate nucleotides has been described in several tissues including human airway epithelial cells $(15,24)$. In the present study, the equal potency of ATP and UTP in stimulating secretion is consistent with the involvement of the 5 '-nucleotide receptor. Furthermore, the activity of UTP suggests that the $\mathrm{P}_{2 Y}$ receptor is not involved since this receptor has been reported to be unaffected by UTP (24), a conclusion further supported by the failure of the potent $\mathrm{P}_{2 \mathrm{r}}$ receptor agonist 2-MeSATP to induce secretion. It is also clear that the ADP-sensitive $\mathrm{P}_{2 \pi}$ receptor is not responsible for the effect seen here since ATP, which caused a striking increase in secretion in the human tissues, has been reported to be an antagonist for this receptor (23). At present, the activity of UTP at the $\mathrm{P}_{2 \mathrm{x}}$ or $\mathrm{P}_{22}$ receptor is unknown and hence the involvement of one of these receptors in the secretory response of goblet cells cannot be excluded. This seems unlikely, however, since mucosal ADP, which is more potent than ATP for the $\mathrm{P}_{2 \mathrm{x}}$ receptor, has been reported to be ineffective at inducing degranulation of canine goblet cells (11). Furthermore, studies in this laboratory suggest that the half-maximal dose $\left(E_{50}\right)$ for ATP in canine tissues is 3 to $4 \mathrm{mM}$ (unpublished observation), a concentration much lower than the $50 \mathrm{mM}$ that has been reported to be the minimum active concentration for the $\mathrm{P}_{2 z}$ receptor (23). Hence, the present study, in combination with similar studies in canine tissues, suggests that luminal triphosphate nucleotides exert their effect on human goblet cells via the 5'-nucleotide receptor.

The results obtained from an ATP challenge of a CF explant and those from studies of UTP on CF and normal tissues (Table 1) indicate that the secretory response of goblet cells to nucleotides is intact in CF. Recently, it has been suggested that CF cells may exhibit impaired cAMP-regulated membrane recycling, including exocytosis (25). The competent exocytosis observed in CF cells in the present study suggests that the response to nucleotides is mediated by a cAMPindependent pathway, possibly $\mathrm{Ca}^{2+}$, since ion transport studies in airway epithelia have shown this pathway to be unaffected by CF (26). This is supported by studies in CF/T43 cells which measured inositol phosphate production in response to ATP and UTP, implicating linkage of the 5 '-nucleotide receptor to a $\mathrm{Ca}^{2+}$-mediated pathway (15). In addition, direct $\mathrm{Ca}^{2+}$ measurements have shown that both normal and CF airway epithelial cells respond to ATP and UTP with increases in intracellular $\mathrm{Ca}^{2+}$ (14).

The ability of ATP and UTP to stimulate mucin secretion in both normal and CF cells is of particular interest in view of the recent finding that these agents are capable of inducing chloride secretion in the CF airway and may therefore be of therapeutic value (27). The intact response of CF tissues to nucleotides reported here suggests that aerosolized nucleotides may induce an increase in mucus secretion into the $\mathrm{CF}$ airway, potentially reducing the beneficial effect of any increase in chloride and fluid secretion. It is possible, however, that due to the hypersecretory nature of $\mathrm{CF}$, the resting level of goblet cell secretion in CF airways in situ is considerably higher than the baseline rate measured in vitro. If this is the case, then any increase in mucin secretion caused by nucleotide therapy would be smaller than that observed in this study 
and may be compensated for by a larger increase in chloride and fluid secretion. Under these circumstances, treatment of CF lung disease with nucleotides may have an overall beneficial effect.

The importance of luminal nucleotide-regulated goblet cell secretion in vivo is not clear. Although significant levels of ATP have been found in rat bronchoalveolar lavage (28), the concentration of ATP in the airway lumen and whether this is altered in normal and pathologic situations is not known. There are several potential sources for ATP in the airway, including nerve terminals releasing ATP as a neurotransmitter, and inflammatory and epithelial cells releasing ATP as a result of damage and cell death or in regulated processes. The contribution of cellular sources to ATP levels in the airway could be of particular significance in pathologic situations associated with inflammation and cell damage. Furthermore, it is interesting to note that ATP has been reported to be capable of stimulating the other components of the mucociliary clearance system, ciliary beat (29), and ion and fluid transport (14). In combination, these findings suggest that the secretory response of goblet cells to ATP may be part of a coordinated action of ATP to increase mucociliary clearance from the airway. Thus, ATP is a potentially important agonist in both normal homeostasis and the response to disease.

Acknowledgments: The authors thank Dr. P.W. Cheng (University of North Carolina) for the generous gift of purified human mucin and Drs. Charles Plopper, Judith St. George and Reen Wu (University of California, Davis) for their kind gift of $17 \mathrm{Bl}$ anti-mucin antibody. This work was supported by Grant HL34322 from the National Heart, Lung and Blood Institute, by Grant 1507 from the Cystic Fibrosis Foundation, and by Glaxo Incorporated.

\section{References}

1. Varsano, S., C. B. Basbaum, L. S. Forsberg, D. B. Borson, G. Caughey, and J. A. Nadel. 1987. Dog tracheal epithelial cells in culture synthesize sulfated macromolecular glycoconjugates and release them from the cell surface upon exposure to extracellular proteinases. Exp. Lung Res. 13:157-184.

2. Kim, K. C., K. Wasano, R. M. Niles, J. E. Schuster, P. J. Stone, and J. S Brody. 1987. Human neutrophil elastase releases cell surface mucins from primary cultures of hamster tracheal epithelial cells. Proc. Natl. Acad. Sci. USA 84:9304-9308.

3. Reid, L. 1959. Chronic bronchitis and hypersecretion of mucus. Lectures on the Scientific Basis of Medicine 8:235-255.

4. Ishihara, H., S. Shimura, M. Satoh, T. Masuda, H. Nonaka, H. Kase, T Sasaki, H. Sasaki, T. Takishima, and K. Tamura. 1992. Muscarinic receptor subtypes in feline tracheal submucosal gland secretion. Am. J. Physiol. 262:L223-L228.

5. Shimura, S., T. Sasaki, H. Ishihara, M. Sato, H. Sasaki, and T. Takishima. 1992. Autonomic innervation to feline tracheal submucosal glands for mucus glycoprotein secretion. Am. J. Physiol. 262:L15-L20.

6. Rogers, D. F., B. Aursudkij, and P. J. Barnes. 1989. Effects of tachykinins on mucus secretion in human bronchi in vitro. Eur. J. Pharmacol. 174:283-286.

7. Pack, R. J., P. S. Richardson, I. C. H. Smith, and S. R. Webb. 1988. The functional significance of the sympathetic innervation of mucous glands in the bronchi of man. J. Physiol. (Lond.) 403:211-219.

8. Tokuyama, K., H.-P. Kuo, J. A. L. Rohde, P. J. Barnes, and D. F. Rogers.
1990. Neural control of goblet secretion in guinea pig airways. Am. $J$. Physiol. 259:L108-L115.

9. Rieves, R. D. J. Goff, T. Wu, P. Larivee, C. Logun, and J. H. Shelhamer. 1992. Airway epithelial cell mucin release: immunologic quantitation and response to platelet-activating factor. Am. J. Respir. Cell Mol. Biol. 6:158-167.

10. Kim, K. C., and B. C. Lee. 1991. $P_{2}$ purinoreceptor regulation of mucin release by airway goblet cells in primary culture. Br. J. Pharmacol. 103:1053-1056.

11. Davis, C. W., M. L. Dowell, M. I. Lethem, and M. Van Scott. 1992. Goblet cell degranulation in isolated canine tracheal epithelium. Response to exogenous ATP, ADP and adenosine. Am. J. Physiol. 262:C1313C1323.

12. St. George, J. A., D. L. Cranz, S. C. Zicker, J. R. Etchison, D. L. Dungworth, and C. G. Plopper. 1985. An immunohistochemical characterization of rhesus monkey respiratory secretions using monoclonal antibodies. Am. Rev. Respir. Dis. 132:556-563.

13. Lin, H., D. M. Carlson, J. A. St. George, C. G. Plopper, and R. Wu. 1989. An ELISA method for the quantitation of tracheal mucins from human and nonhuman primates. Am. J. Respir. Cell Mol. Biol. 1:41-48.

14. Mason, S. J., A. M. Paradiso, and R. C. Boucher. 1991. Regulation of transepithelial ion transport and intracellular calcium by extracellular ATP in human normal and cystic fibrosis airway epithelium. Br.J. Pharmacol. 103:1649-1656.

15. Brown, H. A., E. R. Lazarowski, R. C. Boucher, and T. K. Harden. 1991. Evidence that UTP and ATP regulate phospholipase C through a common extracellular 5'-nucleotide receptor in human airway epithelial cells. $\mathrm{Mol}$. Pharmacol. 40:648-655.

16. Wasano, W., K. C. Kim, R. M. Niles, and J. S. Brody. 1988. Membrane differentiation markers of airway epithelial secretory cells. J, Histochem. Cytochem. 36:167-178.

17. Breuer, R., T. G. Christensen, E. C. Lucey, P. J. Stone, and G. L. Snider. 1987. An ultrastructural morphometric analysis of elastase-treated hamster bronchi shows discharge followed by progressive accumulation of secretory granules. Am. Rev. Respir. Dis. 136:698-703.

18. Kuo, H.-P., J. A. L. Rohde, K. Tokuyama, P. J. Barnes, and D. F. Rogers. 1990. Capsaicin and sensory neuropeptide stimulation of goblet cell secretion in the guinea-pig trachea. J. Physiol. (Lond.) 431:629-641.

19. Wu, R., W. R. Martin, C. B. Robinson, J. A. St. George, C. G. Plopper, G. Kurland, J. A. Last, C. E. Cross, R. J. McDonald, and R. Boucher. 1990. Expression of mucin synthesis and secretion in human tracheobronchial epithelial cells grown in culture. Am. J. Respir. Cell Mol. Biol. 3:467-478.

20. Thornton, D. J., J. R. Davies, M. Kraayenbrink, P. S. Richardson, J. K. Sheehan, and I. Carlstedt. 1990. Mucus glycoproteins from 'normal' human tracheobronchial secretion. Biochem. $J$. 265:179-186.

21. Carlstedt, I., and J. K. Sheehan. 1984. Is the macromolecular architecture of cervical, respiratory and gastric mucins the same? Biochem. Soc. Trans. 12:615-617.

22. Cockcroft, S., and B. D. Gomperts. 1980. The ATP ${ }^{4-}$ receptor of rat mast cells. Biochem. J. 188:789-798.

23. Gordon, J. L. 1986. Extracellular ATP: effects, sources and fate. Biochem J. 233:309-319.

24. O'Connor, S. E., I. A. Dainty, and P. Leff. 1991. Further subclassification of ATP receptors based on agonist studies. Trends Pharmacol. Sci. $12: 137-141$.

25. Bradbury, N. A., T. Jilling, G. Berta, E. J. Sorscher, R. J. Bridges, and K. L. Kirk. 1992. Regulation of plasma membrane recycling by CFTR. Science 256:530-532.

26. Boucher, R. C., E. H. C. Cheng, A. M. Paradiso, M. J. Stutts, M. R. Knowles, and H. S. Earp. 1989. Chloride secretory response of cystic fibrosis human airway epithelia. J. Clin. Invest. 84:1424-1431.

27. Knowles, M. R., L. L. Clarke, and R. C. Boucher. 1991. Activation by extracellular nucleotides of chloride secretion in the airway epithelia of patients with cystic fibrosis. N. Engl. J. Med. 325:533-538.

28. Rice, W. R., M. Burhans, and J. R. Wispe. 1989. Effect of oxygen exposure on ATP content of rat bronchoalveolar lavage. Pediatr. Res. $25: 396-398$.

29. Villalon, M., T. R. Hinds, and P. Verdugo. 1989. Stimulus-response coupling in mammalian ciliated cells: demonstration of two mechanisms of control for cytosolic $\left[\mathrm{Ca}^{2+}\right]$. Biophys. J. 56:1255-1258. 